\title{
Reactions to a dyadic power structure'
}

WILLIAM P. SMITH

IANDERBILT UNIVERSITY

In a dyad where power and counterpower were determined by the value of each party's alternatives to the interaction, (a) subjects with a more valuable alternative liked their partner less and were more likely to choose the alternative than were those with a less valuable altemative; (b) subjects with little power both gave a higher estimate of their outcome from the interaction and tended to use their power more punitively than did those with much power.

A person's reactions to group membership should be strongly influenced by the nature of his interdependence with other group members, according to Thibaut \& Kelley (1959). Each member of a group must receive better reward-cost outcomes from the group than from any known alternative to it if he is to maintain his affiliation with the group. Further, the more reward a member believes the group can offer him above what he believes he could obtain from his best alternative to the group, the greater is his dependence on the group (and, therefore, the greater is the group's power over him). Similarly, a member's power over another member is defined by the difference between the reward the former can offer the latter, and the latter's alternative to the group. If any member's outcomes typically fall below what he feels he could get from his best alternative, he will leave the ongoing group relationship for his best alternative.

A group member will not only move from one group to another in his attempts to obtain maximally good outcomes for himself, but will also attempt to change his outcomes from a particular group relationship by shaping other members' behavior through reward and punishment. It is assumed that a group member will in some way take account of the values of his own and other members' alternatives in his efforts to affect the rewards and punishments of other group members. Specifically, he will avoid punishing others (a) if such punishment is expected to lead others to seek their best alternative to the group, or (b) if he is vulnerable to others' retaliation by virtue of his own poor alternative. Furthermore, where for such reasons a member is reluctant to use his punishment, he will expect poorer outcomes from the group than will a member who expects to be able to control his outcomes from other group members by using reward and punishment.

The implications of this view are that, given a certain range of rewards available from a group, and increasingly poor rewards from that group, (a) the likelihood of a member's leaving that group for his best alternative is a direct function of the value of his best alternative, (b) the willingness of the member to use his power to punish another group member is inversely related to the value of the latter's best alternative as perceived by the first member, and directly related to the value of his own alternative, and (c) since reluctance to withhold reward should result in a low expectancy for reward from the group, a member should show greater appreciation for a given level of outcomes he receives from the group, the higher in value are other members' best alternatives to the group, and the lower in value is his own alternative. This greater appreciation may be expressed in higher ratings of satisfaction with the group, and greater liking for other group members.

Method

A laboratory experiment was conducted with 60 undergraduate students of both sexes.

Each S was led to believe that he would, on a number of trials, send poker chips of one color to another person and receive chips of another color from that person, termed his partner. The partner was actually fictitious; the $\mathrm{E}$ confiscated chips sent by the $\mathrm{S}$, and administered chips to him according to a prearranged schedule.

The experiment was presented to Ss as an analogue to an organization in which they should consider themselves executives. Each chip they sent or received was to be viewed as a unit of praise or help; in addition, the chips received by the $S$ were worth $1 \notin$ to him, and those he sent were said to be worth $1^{\text {t }}$ each to his partner. It cost nothing to send chips, and each party could supposedly send up to 12 chips per trial. No communication aside from sending chips was allowed; it was pointed out to each $S$ that the only way he could affect the number of chips he received from his partner was through the number of chips he sent to him. On each trial the $S$ and his partner exchanged chips simultaneously.

The $S$ was told that both he and his partner had an alternative source of valued chips, a hypothetical machine called "Joe." On any trial, the S (and/or supposedly, his partner) could choose to receive chips from Joe rather than from the other member of the dyad.

In the High Power (HP) condition, Ss were told that their partner's Joe was worth 4 t per trial; in the Low Power (LP) condition, partner's Joe was supposedly worth $8 \mathrm{t}$. In the High Dependence (HD) condition, the $S$ could obtain about $4 \%$ per trial from Joe, while in the Low Dependence (LD) condition, 8 was available to the $S$ from Joe. The resultant design was 2 by 2 factorial.

In all conditions, the prearranged schedule of out- 
comes from the partner was identical. For trials $1-10,11-20,21-30,31-40$ respectively, the mean number of chips from the schedule was 10.0, 7.5, 5.0, and 2.5. All Ss received all 40 trials from the schedule. When a $S$ chose to receive from Joe an extra trial was inserted into the schedule, on which the $S$ received chips appropriate to the value of Joe. At the end of the 40 trials from the partner, a post-experimental questionnaire, composed primarily of rating scales for the measurement of satisfaction, was administered. Finally, a full explanation of the study was given to Ss, and a nominal payment was made.

\section{Resulfs}

An analysis of variance of the number of trials upon which a choice to receive from Joe occurred revealed that LD Ss, as predicted, chose Joe more often than did HD Ss $(F=6.53, d f=1 / 56, p<.05)$. This difference was strongest during the last two blocks of trials, as indicated by an interaction between dependence and trials $(F=9.53, \mathrm{df}=3 / 168, \mathrm{p}<.01)$.

It was assumed that a S's attempts to control the behavior of his partner would be reflected in his use of the highest and lowest rewards he could provide for his partner. Thus the difference between the highest and lowest reward a $S$ provided per block of trials was computed; analysis of variance indicated that, contrary to predictions, LP Ss used a wider range of rewards than did $H P$ Ss $(F=4.93, d f=1 / 56$, $p<.05)$. Analysis of the highest and lowest outcomes provided respectively give some suggestion that this difference could be traced to a lower outcome provided by $L P$ Ss $(F=3.72, d f=1 / 56, .05<p<.10)$. Finally, there was some suggestion that although the average number of chips sent by all Ss dropped over trials, the rate was greater for LP than for HP Ss $(F=2.49, \mathrm{df}=3 / 168, .05<\mathrm{p}<.10)$ for trials by power interaction. In short, there is some evidence that LP Ss used their power more, especially in a punitive way, than did HP Ss.

Responses to post-experimental questionnaire items indicated that (a) HD Ss were somewhat more satisfied $(p<.20)$ than LD Ss; (b) HD Ss thought they would like their partner more than did LD Ss $(F=4.05$, df $=1 / 56, p<.05$ ); (c) the estimate made by LP Ss of the number of chips they received per trial from the partner was higher than that made by HP Ss ( F = 5.10, $\mathrm{df}=1 / 56, \mathrm{p}<.05$ ).

\section{Discussion}

In general, the findings indicate that Ss do take account of their own alternatives to the group in two ways. Not surprisingly, the more valuable that alternative, the more likely it is to be taken when outcomes from the group are poor. In addition, if it may be assumed that the greater liking for the partner, and slightly greater satisfaction with the outcomes he provided reflects greater appreciation for the outcomes provided, it can be inferred that as the value of a person's alternative declines, so does the value of the outcomes he expects from the group.

There is also evidence that Ss took account of the value of the partner's alternative-but in a surprising way, since LP Ss were more punitive in their use of power than were HP Ss. It may be that LP Ss felt a stronger need to change the partner's behavior-a need so strong that it overrode their fear of alienating the partner. Such a need might result from LP Ss' realization that the poor outcomes from the partner could reflect an attempt by him to take his alternative while giving them poor outcomes, thus receiving not only fairly good outcomes absolutely (8 $\$$ per trial), but better outcomes than the LP Ss. In other words, LP Ss may have suspected a competitive orientation (Deutsch, 1962), and may have felt that it called for stringent measures. HP Ss would find such a suspicion less salient, since the partner could guarantee himself only $4 \mathrm{c}$ per trial with such a strategy. Some Ss did express some suspicion that the partner was competitive, but no record of this was kept at the time. It may be that possession of a valuable alternative by another always excites suspicion of competitiveness, or the phenomenon may be restricted to short term relationships, as in a laboratory group.

Aside from their greater use of power, LP Ss do show some evidence of a low expectancy level, in that their estimates of the number of chips received per trial from the partner are higher than the estimates made by HP Ss.

\section{References}

Deutsch, M. Cooperation and trust: Some theoretical notes. In $M$. Jones (Ed.), Nebraska symposium on motivation, 1962, Lincoin: University of Nebraska Press, 1962.

Thibaut, J. W., \& Kelley, H. H. The social psychology of groups. New York: Wiley, 1959.

\section{Note}

1. This research was supported by a grant from the National Science Foundation (GS-201) to the author. 